\title{
RESEARCH
}

Open Access

\section{"I want to get better, but...": identifying the perceptions and experiences of people who inject drugs with respect to evolving hepatitis $C$ virus treatments}

Trevor Goodyear ${ }^{1,2}$, Helen Brown ${ }^{1}$, Annette J. Browne ${ }^{1}$, Peter Hoong ${ }^{2}$, Lianping Ti ${ }^{2,3}$ and Rod Knight ${ }^{2,3^{*}}$

\begin{abstract}
Background: The advent of highly tolerable and efficacious direct-acting antiviral (DAA) medications has transformed the hepatitis $\mathrm{C}$ virus (HCV) treatment landscape. Yet, people who inject drugs (PWID) - a population with inequitably high rates of HCV and who face significant socio-structural barriers to healthcare access - continue to have disproportionately low rates of DAA uptake. The objective of this study is to explore how PWID with lived experience of HCV perceive and experience DAA treatment, in a setting with universal coverage of these medications since 2018.

Methods: Informed by a critical interpretive framework, we thematically analyze data from in-depth, semistructured interviews conducted between January and June 2018 in Vancouver, Canada, with a purposive sample ( $n=56)$ of PWID at various stages (e.g., pre, peri, post) of DAA treatment.

(Continued on next page)
\end{abstract}

\footnotetext{
* Correspondence: bccsu-rk@bccsu.ubc.ca

This document is based on the Uniform Requirements for Manuscripts

Submitted to Biomedical Journals. Click here for more information regarding

the ICMJE requirements.

${ }^{2}$ British Columbia Centre on Substance Use, 400-1045 Howe St, V6Z 2 A9

Vancouver, BC, Canada

${ }^{3}$ Department of Medicine, University of British Columbia, Vancouver, Canada

Full list of author information is available at the end of the article
}

(c) The Author(s). 2021 Open Access This article is licensed under a Creative Commons Attribution 4.0 International License, which permits use, sharing, adaptation, distribution and reproduction in any medium or format, as long as you give appropriate credit to the original author(s) and the source, provide a link to the Creative Commons licence, and indicate if changes were made. The images or other third party material in this article are included in the article's Creative Commons licence, unless indicated otherwise in a credit line to the material. If material is not included in the article's Creative Commons licence and your intended use is not permitted by statutory regulation or exceeds the permitted use, you will need to obtain permission directly from the copyright holder. To view a copy of this licence, visit http://creativecommons.org/licenses/by/4.0/ The Creative Commons Public Domain Dedication waiver (http://creativecommons.org/publicdomain/zero/1.0/) applies to the data made available in this article, unless otherwise stated in a credit line to the data. 
(Continued from previous page)

Results: The analysis yielded three key themes: (i) life with HCV, (ii) experiences with and perceptions of evolving HCV treatments, and (iii) substance use and the uptake of DAA treatments. First, participants described how health and healthcare conditions, such as the deprioritizing of HCV (e.g., due to: being asymptomatic, healthcare provider inaction, gatekeeping) and catalysts to care (e.g., symptom onset, treatment for co-morbidities) shaped DAA treatment motivation and access. Second, participants described how individual and community-level accounts of evolving HCV treatments, including skepticism following negative experiences with Interferon-based treatment and uncertainty regarding treatment eligibility, negatively influenced willingness and opportunities to access DAAs. Concurrently, participants described how peer and community endorsement of DAAs was positively associated with treatment uptake. Third, participants favoured HCV care that was grounded in harm reduction, which included the integration of DAAs with other substance use-related services (e.g., opioid agonist therapy, HIV care), and which was often contrasted against abstinence-focused care wherein substance use is framed as a contraindication to HCV treatment access.

Conclusions: These findings underscore several equity-oriented healthcare service delivery and clinician adaptations that are required to scale up DAAs among PWID living with HCV, including the provision of harm reduction-focused, non-stigmatizing, integrated, and peer-led care that responds to power differentials.

Keywords: Hepatitis C, Direct-acting antivirals, Treatment, People who inject drugs, Substance use, Harm reduction, Qualitative research, Equity, Ethics, Health services

\section{Introduction}

Hepatitis $\mathrm{C}$ virus (HCV) infection remains a major contributor to worldwide morbidity and mortality [1]. While potentially curative HCV treatments have been available for nearly two decades, the previous and longstanding generation of Interferon-based treatments demonstrated limited effectiveness ( 50\% cured), required prolonged treatment for up to 48 weeks, and had significant side effects (e.g., flu-like symptoms, insomnia, impaired mood) [2]. As such, rates of Interferon-based treatment uptake have been as low as $15 \%$ among people living with $\mathrm{HCV}$ [3], and even lower among populations who are most marginalized with respect to treatment access, including people who inject drugs (PWID) $[4,5]$. The recent advent of all-oral direct-acting antiviral (DAA) HCV treatments has renewed optimism for transforming the global $\mathrm{HCV}$ care landscape. These novel treatments have minimal side effects and contraindications and are highly effective in achieving HCV cure $[6,7]$. Accordingly, the scale-up of DAAs constitutes a critical component underlying the World Health Organization's goal to eliminate $\mathrm{HCV}$ as a major public health threat by 2030 [8].

Public health efforts to reduce the global burden of HCV must be firmly grounded in equity and social justice. Already, there have been calls to prioritize DAA treatment scale-up efforts with populations who face inequities in $\mathrm{HCV}$ prevalence, incidence, and healthcare access [9, 10]. PWID have been widely recognized as one such "priority population" - particularly, in regions wherein $\mathrm{HCV}$ rates among this population remain high [10-13]. Due to the sharing of injection drug equipment and the lack of accessible harm reduction services (e.g., needle and syringe distribution programs, opioid agonist therapy [OAT]) in various global settings, PWID continue to be inequitably impacted by blood-borne infections, including $\mathrm{HCV}$ and human immunodeficiency virus (HIV) [14, 15]. Indeed, PWID are estimated to comprise 6.1 million $(8.5 \%)$ of the 71.1 million prevalent chronic HCV cases worldwide [11, 16]. And in many 'western' countries, including Canada, where, as of 2015, approximately $53 \%$ of PWID were estimated to be living with HCV [11], injection drug use is now the principal route of incident HCV transmission $[8,17]$.

While Interferon-free $\mathrm{HCV}$ therapies represent a "game changer" for PWID living with $\mathrm{HCV}$, a series of barriers to equitable DAA treatment access remain. For instance, recent studies have described key implementation challenges related to specialist-centered models of HCV care, lack of on-site phlebotomy services, finite resources to develop a comprehensive HCV cascade of care, and onerous diagnostic and prescription-related eligibility requirements for accessing DAAs [18-20]. A small but growing body of empirical evidence with PWID participants also has identified the ways in which individual and socio-contextual factors influence DAA treatment access and uptake. For example, previous qualitative studies - few of which are from the current DAA treatment era - have examined how perceptions and knowledge levels related to various aspects of $\mathrm{HCV}$ and its management (e.g., disease transmission and progression, medication side effects, treatment eligibility and conditions, potential re-infection) are important determinants of $\mathrm{HCV}$ treatment uptake [21-24]. More generally, disinclination to undergo DAA treatment 
among PWID can stem from being asymptomatic of $\mathrm{HCV}$, the prioritization of other health and social issues (e.g., co-morbidities, housing, childcare), and experiences of stigma and discrimination when accessing services [21, 25, 26]. Of particular concern, available evidence indicates that healthcare providers tend to view active substance use as a contraindication to DAA treatment eligibility, including due to a presumed lack of stability and/or capacity for PWID to adhere to treatment regimens, and the anticipated potential for sustained liver damage and/or re-infection following HCV cure [27-29].

Taken as a whole, PWID continue to face a set of interconnected challenges that restrict access to $\mathrm{HCV}$ care, including DAA therapies. As a consequence of these healthcare access inequities, PWID populations experience low rates of DAA treatment uptake, despite paradoxically experiencing both a high prevalence of $\mathrm{HCV}$ and a well-documented willingness to undergo treatment $[8,15,30]$. To address this noteworthy gap in equitable health and healthcare access among PWID living with $\mathrm{HCV}$, there is a need for knowledge about how PWID's experiences are unfolding within and influenced by evolving $\mathrm{HCV}$ care landscapes. The objective of this study is therefore to explore how PWID with lived experience of $\mathrm{HCV}$ perceive and experience DAA treatments, in a setting with universal coverage of these medications since 2018.

\section{Methods}

\section{Theoretical perspectives}

This study is informed by selected critical theoretical perspectives on health equity and social justice [3133]. The first of these theoretical perspectives, as described in detail by Browne \& Reimer-Kirkham [31], relates to dialectical social justice and provides a scaffolding for social justice scholarship to include both deconstructive (i.e., critical of oppression) and reconstructive (i.e., emancipatory) aims and analytical processes. The second theoretical perspective, by Varcoe and colleagues [32], outlines an equity-transformative framework for further bridging gaps between critical scholarship and practice (i.e., between knowledge and action). Building on these conceptualizations of social justice and health equity, we approach this study with a view toward advancing equity-oriented healthcare [33] with PWID who have lived experience of HCV. Described in depth elsewhere [33], equity-oriented healthcare and research is fundamentally concerned with addressing: "the effects of structural inequities (such as poverty), including the inequitable distribution of the determinants of health (e.g., income and housing) that sustain health inequities; the impact of multiple and intersecting forms of racism, discrimination and stigma [. .] on people's access to services and their experiences of care; and the frequent mismatches between dominant approaches to care [. .] and the needs of people who are most affected by health and social inequities." Within the current study, we operationalize these theoretical perspectives [31-33] to interrogate how HCV-related treatment experiences are embedded within the socio-structural conditions of PWID's lives, and also to direct our analytical gaze toward the distinct contexts in which equitable access to DAAs is (or is not) realized for PWID with lived experience of HCV.

We also approach this study within a critical interpretive framework informed by our direct clinical and research experiences working with communities of PWID, including as public health researchers and as nurses. Here, we employ a thematic analysis approach that is grounded in a social constructivist epistemology $[34,35]$. We operationalize this methodology by drawing on participants' lived experiences and our interpretations as analysts, and by inductively approaching data analysis in a way that is firmly grounded in our theoretical and axiological positioning as critical health researchers. Through this lens, we interpret the lived experiences of $\mathrm{HCV}$ care among PWID to identify strengths-based and contextually-informed strategies for promoting equityoriented healthcare with this population, particularly in the context of $\mathrm{HCV}$.

\section{Study setting}

This research was conducted in Metro Vancouver, British Columbia (BC), Canada, a metropolitan area with an approximate population of $2,463,431$ people [36]. In Canada, the majority of healthcare services, including those under the umbrella of $\mathrm{HCV}$ care, are publicly funded and universally offered. Importantly, however, Canada does not have a federal pharma-care program, so publicly funded medication coverage, when available, is determined at the provincial level. In 2018, the province of $\mathrm{BC}$ removed restrictions from the $\mathrm{BC}$ PharmaCare program to DAA access and approved the universal coverage of several DAA treatment formulations for all British Columbians living with HCV [37]. This policy change expanded treatment access to the 53 , 441 HCV-diagnosed-individuals living in BC in 2018, among whom $18,609(34.8 \%)$ reported current or past injection drug use [38]. However, also in 2018, only 5, 200 (27.9\%) individuals within this population of PWID living with $\mathrm{HCV}$ were able to access and begin treatment (with either DAAs or Interferon-based therapies), signaling an ongoing gap in the $\mathrm{HCV}$ cascade of care for this priority population [38]. 
Given the colonial context of Canada, it is important to understand the structurally-embedded nature of the inequities experienced by Indigenous ${ }^{1}$ PWID living with HCV, broadly, as well as the overrepresentation of Indigenous Peoples within the current study, specifically. Across Canada, Indigenous Peoples are inequitably impacted by substance use and HCV. As described in detail elsewhere (e.g., $[26,39,40])$, colonial policies and institutions in Canada (e.g., the Indian Act, Indian Residential Schools and Hospitals, the current child welfare and criminal justice systems, ongoing treaty violations) have disrupted the wellbeing, rights, and self-determination of Indigenous Peoples. Concomitantly, these and other forms of structural violence have created and sustained the conditions in which Indigenous Peoples in Canada face barriers to determinants of good health, thereby contributing to significantly higher morbidity and mortality rates among Indigenous Peoples relative to nonIndigenous people $[41,42]$. Within this context, systemic racism - including in healthcare settings - has exacerbated the harms experienced by Indigenous Peoples who use/inject drugs, as evidenced by inequitable rates of $\mathrm{HCV}, \mathrm{HIV}$, overdoses, and criminalization related to drug offences [26, 43-46]. As one example, recent public health surveillance data from the Canadian provinces of Saskatchewan and Ontario estimated that $\mathrm{HCV}$ rates are 6-11 times higher among First Nations Peoples relative to non-Indigenous people [26, 47, 48]. Further still, recent research has demonstrated that Indigenous Peoples in Canada are up to $50 \%$ less likely than non-Indigenous people to be able to access and begin HCV treatment $[49,50]$, and three times more likely to die without ever having accessed HCV care $[26,51,52]$. It is in this context of ongoing harms associated with systemic racism and related inequities that the current study is situated.

\section{Sampling and recruitment procedures}

Drawing on a stratified purposive sampling strategy [53], we led targeted recruitment of specific participant subgroups (i.e., stratified by gender identity, HIV serostatus, and stage of $\mathrm{HCV}$ treatment) from three large prospective cohort studies in Metro Vancouver: the Vancouver Injection Drug Users Study (VIDUS), the AIDS Care Cohort to Evaluate access to Survival Services (ACCESS) study, and the Preservation of Sustained Virologic Response (Per-SVR) study. As described in detail elsewhere [54], VIDUS and ACCESS are open communityrecruited prospective cohort studies that, since 1996 and 2005, respectively, have conducted research (e.g., through baseline and semi-annual interviewer-

\footnotetext{
${ }^{1}$ The term "Indigenous" refers to First Peoples internationally. We use this term to broadly refer to the diverse groups of First Nations, Métis, Inuit, and other Indigenous Peoples living in Canada.
}

administered questionnaires, testing for $\mathrm{HCV}$ and other blood-borne infections, and clinical monitoring) with HIV-negative (VIDUS) and HIV-positive (ACCESS) people who use/inject drugs. Similarly, initiated in 2017, the Per-SVR study [55] is a prospective longitudinal cohort of people with lived experience of $\mathrm{HCV}$ and who have completed or who are currently undergoing treatment with DAAs.

VIDUS, ACCESS, and Per-SVR research staff identified prospective participants by querying their respective cohort study databases. During baseline and follow-up visits for their respective studies, research staff informed prospective participants about the current qualitative study. To be eligible for inclusion in this study, participants were required to live within Metro Vancouver, be 19 years of age or older, be fluent in English, selfidentify as a person who injects drugs, have lived experience with $\mathrm{HCV}$, and indicate that they were either (1) considering accessing DAA treatments, (2) presently undergoing DAA treatment, or (3) had recently completed DAA treatment. After participants contacted our research team, we provided additional study information, confirmed eligibility, and scheduled interviews. Participants provided written informed consent prior to data collection activities and were remunerated with a CDN $\$ 30$ honorarium. Ethics approval was obtained from the University of British Columbia Behavioural Research Ethics Board (\#H16-02943).

\section{Data collection}

Between January and June of 2018, our study's research coordinator (co-author $\mathrm{PH}$ ) and principal investigator (co-author RK) conducted 56 in-depth, semi-structured interviews that lasted 30-60 min. We held interviews at our research offices in Vancouver's Downtown Eastside. Our critical theoretical and axiological positioning informed the design of our interview guide, which sought to elicit comprehensive discussions about participants' perceptions and experiences with DAA treatments, $\mathrm{HCV}$ care, and health and healthcare access more generally. Our interview questions related generally to how participants had become aware of and informed about DAA treatments. In addition, we asked participants to describe the circumstances and contexts in which they had accessed (or had not been able to access) DAA treatments. At this point in time, we prompted participants to elaborate on how various individual and relational (e.g., provider-patient dynamics; apprehensions related to previous experiences with Interferon-based therapies, as well as concerns about potential side effects) influenced their experiences and perspectives related to DAA therapies. In addition, we encouraged participants to discuss how broader contextual features of their lives influenced their experiences with $\mathrm{HCV}$ and wellbeing more 
generally; in doing so, we sought to elicit discussion of how socio-structural factors (e.g., features of healthcare delivery systems, peer and community supports, treatment eligibility criteria, marginalization, stigma) influence opportunities to access, adhere to, and complete DAA regimens. Participants also filled out an 8-item socio-demographic questionnaire, which included items related to age, ethnicity, HIV serostatus, HCV treatment status, and sexual and gender identity.

\section{Data analysis}

Data collection and preliminary analysis were conducted iteratively, with later interviews helping to identify gaps in our sample and inform subsequent data collection. This iterative process also informed our assessments of whether we had collected sufficient data to comprehensively address our study objective, as well as our eventual decision to cease recruitment. Interviews were audio-recorded, transcribed verbatim, accuracy checked, anonymized, and securely and digitally stored with identifying details removed. We uploaded the interview data to NVivo 12 software, which we used to manage the analysis. At early stages of the analysis, co-author $\mathrm{PH}$, the lead author (TG), and one non-author research assistant (NT) began by reading and re-reading the interview transcripts to familiarize themselves with the data. $\mathrm{PH}$ and NT inductively organized the data into patterns, which were then assigned substantive open codes (e.g., related to: background participant information, experiences living with $\mathrm{HCV}$, experiences and perceptions of DAAs, barriers and facilitators associated with DAA treatment access and uptake) [35]. Each transcript was then independently coded by either $\mathrm{PH}$ or NT, using the data-driven coding schematic. With consultation from senior co-authors RK, $\mathrm{HB}$, and AJB, TG then employed axial coding [34, 35] to organize initial codes into "trees" that represented groups of related concepts and categories, which provided a foundational schematic for the analysis. In doing so, we used constant comparative techniques [34] to further distil and contextualize emerging themes.

Throughout data analysis, we explored each key theme more fully by engaging with analytical questions that stemmed from our equity-oriented theoretical perspectives [31-33], including: (i) How do perceptions about $\mathrm{HCV}$ and its treatments (i.e., both historical and current) shape PWID's attitudes and experiences with DAAs? (ii) What key considerations and socio-contextual factors influence opportunities to access and complete DAA treatment? (iii) Under what conditions and in which contexts is equitable access to DAAs and wellbeing more generally for PWID realized? As the analysis proceeded, we addressed discrepancies between emergent themes through debriefing processes at team meetings. In addition, the lead author employed a series of inductive approaches (e.g., returning to the data for nuance and context, iteratively contrasting emerging themes against what is already documented in related empirical and theoretical literature bases) to construct and refine central themes, which we present below.

\section{Results}

A total of 56 PWID with lived experience of HCV were included in this analysis. Table 1 provides an overview of the socio-demographic characteristics of this sample. In addition, although not explicitly asked in our socio-demographic questionnaire, our interviews surfaced that many participants had experienced - and, in most cases, were still experiencing - significant socio-economic hardship, including living on very low incomes and in inadequate housing situations (e.g., couch surfing, shelters, outside). The social context of participants' lives is surfaced throughout the analysis below, where we offer the findings in three thematic sections: (i) life with $\mathrm{HCV}$, (ii) experiences with and perceptions of evolving $\mathrm{HCV}$ treatments, and (iii) substance use and the uptake of DAA treatments. Each participant quotation is accompanied by a brief description of the participant's sociodemographic profile and a researcher-assigned numerical identifier.

\section{Life with HCV: "We're not really given all the information"} As the interviews began, participants reported having variable and sometimes limited amounts of clinical information related to $\mathrm{HCV}$ and its treatments. Among participants who had not yet accessed DAA treatment, in particular, several described experiences in which they had not been adequately informed by their healthcare providers about the meaning and potential impact of $\mathrm{HCV}$ (e.g., symptoms, transmissibility, prognosis, treatment options). Indeed, some of these participants even indicated that, through the interview questions and prompts regarding DAA treatments for the present study, they were being informed of DAAs for the very first time. Here, participants also described how the prevalent and often asymptomatic nature of $\mathrm{HCV}$ within their communities had led to HCV care being conventionalized and deprioritized by some healthcare providers. These participants further postulated that this "downplaying" of HCV had inadvertently affected the amount of HCV-related information they had been given and the extent to which they had been engaged by their healthcare providers in HCV care. Some participants indicated that HCV care continues to be deprioritized in today's healthcare context, relative to other health 
Table 1 Characteristics of participants

\begin{tabular}{|c|c|c|}
\hline Participants & & 56 \\
\hline Age (average, range) & & $49(31-66)$ Years \\
\hline & Ethnocultural identity & \\
\hline First Nations & & $28(50 \%)$ \\
\hline Métis & & $3(5.4 \%)$ \\
\hline Black & & $1(1.8 \%)$ \\
\hline White & & 19 (33.9\%) \\
\hline Declined to answer & & $5(8.9 \%)$ \\
\hline & $\mathrm{HCV}$ treatment status & \\
\hline Pre-treatment ${ }^{l}$ & & $25(44.6 \%)$ \\
\hline Peri-treatment & & $12(21.4 \%)$ \\
\hline Post-treatment & & 19 (33.9\%) \\
\hline & HIV serostatus & \\
\hline Positive & & $27(48.2 \%)$ \\
\hline Negative & & $29(51.8 \%)$ \\
\hline & Sexual identity & \\
\hline Heterosexual/straight & & $42(75 \%)$ \\
\hline Bisexual/bicurious & & $4(7.1 \%)$ \\
\hline Lesbian & & $1(1.8 \%)$ \\
\hline Gay & & $1(1.8 \%)$ \\
\hline Two-Spirit $^{2}$ & & $2(3.6 \%)$ \\
\hline Other ${ }^{3}$ & & $2(3.6 \%)$ \\
\hline Declined to answer & & $4(7.1 \%)$ \\
\hline & Gender identity & \\
\hline $\mathrm{Man}^{4}$ & & $29(51.8 \%)$ \\
\hline Woman $^{5}$ & & $26(46.4 \%)$ \\
\hline Two-Spirit ${ }^{2}$ & & $1(1.8 \%)$ \\
\hline
\end{tabular}

${ }^{1}$ This category includes one participant whose completed DAA treatment regimen did not result in cure, one participant who prematurely ceased DAA treatment due to adverse side effects, and one participant who re-acquired HCV after being cured with Interferon-based therapies several years prior. All of these participants expressed intent to (re)access DAA treatment.

2"Two-Spirit" is an umbrella term intended to encapsulate a range of Indigenous gender diverse and non-normative sexual orientations [56]. There is no singular definition of this term, as its use varies across and within Indigenous Peoples and communities. Two participants in this study described their sexual identities as Two-Spirit, whereas another participant used this term to refer to their gender identity.

${ }^{3}$ In this category, one participant identified as transgender and another participant identified as androgynous. Although we associate these terms with gender identity and expression, this table presents the sexual identities indicated by participants themselves.

${ }^{4}$ All men who participated in this study identified as cisgender.

${ }^{5}$ One woman who participated in this study identified as transgender, whereas the remaining women identified as cisgender.

concerns (e.g., overdose, HIV). One 53-year-old woman, who had not yet been able to access HCV treatment, described this critical information gap when outlining her experience of being diagnosed with $\mathrm{HCV}$ by her family physician:
Hep $C$ is the least of the dangers [compared to other illnesses], but it doesn't mean it's not dangerous. And we're not really given all the information about what organ it [HCV] hurts, what exemplifies it, or what could help on a daily basis to avoid it. Like, is it a growth, is it a, you know, a virus, like a liquid, or is it hardening or, you know, I don't know any of those things (Participant_17).

Conversely, some participants described healthcare interactions in which they had been "overloaded" with information related to $\mathrm{HCV}$ and other aspects of their health, including, in particular, substance use and HIV. These participants described instances in which they had been unsatisfactorily supported by their healthcare providers and how, within this context, the shock of being diagnosed with HCV - and, in many cases, also HIV had caused them to "close down" and not retain important information related to their illness and/or potential treatment options. More generally, several participants pointed to the ways in which previous and ongoing negative experiences within clinical encounters could impact their subsequent experiences and trajectories of care. For example, participants described highly dehumanizing clinical encounters (i.e., that lacked respect, empathy, and recognition of client choice) with healthcare providers, which they tended to associate with their ongoing mistrust of some healthcare providers. As such, participants emphasized that negative experiences with healthcare providers were strongly tied to a deep hesitancy they have around seeking follow-up HCV care, including DAA treatment. As one prominent example, one 55-year-old woman undergoing $\mathrm{HCV}$ treatment recounted the context in which, while in her 30s, she and her newborn son had both been tested for HCV and HIV:

I found out about my hepatitis $C$ when I found out I had HIV. [. .] I went and seen him [the physician], and he tested my son, he tested me. He said, "Come back in two weeks." And when that two weeks came by, I went and seen him [again]. He goes, "Well, I've got some good news and I've got some bad news." And I said, "What's that?". He says, "Well, first of all, you have hep C." I said, "Okay." And he goes, "And your son's gonna live, but you, you're gonna die." I said, "What?" [laughs]. He goes, "Because you have HIV." I said, "Okay." And then, when he said I was gonna die, I just closed right down. . I didn't hear a word what he said (Participant_10).

As participants' stories further unfolded, a subset described how, despite having lived with HCV for years or even for decades, they had largely been asymptomatic of 
$\mathrm{HCV}$, and therefore had tended to de-prioritize seeking HCV-related information and/or treatment. In describing how she had lived with $\mathrm{HCV}$ for more than 20 years, one person reflected:

"I wasn't really worried about it [HCV] because I was young and still healthy" (Participant_19; 46year-old woman, also living with HIV, completed $\mathrm{HCV}$ treatment).

Some of these participants described how they had nonetheless begun treatment after being encouraged to do so by their healthcare providers during hospitalization or while accessing community-based healthcare for other co-morbidities. Characterized within these descriptions was a sense that decentralized, primary care-oriented $\mathrm{HCV}$ care had become increasingly commonplace in their local healthcare context. Alongside these healthcare system adaptations, many participants also indicated that their experiences of aging, the intensifying burden of late-onset and chronic $\mathrm{HCV}$ symptoms (e.g., fatigue, insomnia, depression, pain, jaundice), and, in many cases, the increasing toll and stress of living on a low income and/or in substandard housing had shaped a set of conditions in which they felt they needed to access HCV treatment. Here, one 45-year-old man, who had been living with HCV for more than 20 years prior and who had not yet been able to access treatment, described the subtle but gradual and regressive nature of $\mathrm{HCV}$ disease progression, which reinforced his present motivation to seek medical attention:

I just kind of [thought], like, "Oh, I'm young, you know. I'll ignore it [HCV]. I'll be alright and I'll fight it off. I'll be alright, you know. Now, I'm kind of wanting to [learn more about it], because I'm not getting frigging younger here, right? (Participant_04).

In summary, participants described how their healthcare interactions and the timing and impact of their symptoms while living with HCV impacted their knowledge, motivations, and experiences with $\mathrm{HCV}$ care access, including DAAs. In considering participants' portrayals of life with $\mathrm{HCV}$, we continue the analysis below by explicitly identifying participants' perceptions and experiences related to $\mathrm{HCV}$ treatments.

\section{Experiences with and perceptions of evolving HCV} treatments: "The new one is way better than the old one" The majority of participants described how, within the last 1-2 years (i.e., contemporaneously with the introduction of universal access to DAAs in BC, in 2018), they had become aware of DAA treatments through discussions with members of their peer and healthcare networks. Yet, several participants described continued uncertainty as to whether or not they were eligible for DAA treatments - particularly, if they had previously been denied Interferon- and/or DAA-based HCV treatments. Here, several participants also described a sense of ambiguity related to where, when, and how they could access DAA treatment. Amidst these descriptions, many participants' stories chronicled the challenge of identifying and accessing healthcare services and providers with whom they could potentially begin DAA treatment regimens. For example, the above participant further explained:

I don't know where to get it [DAAs], or if there's any out there, or if we're eligible for it. There's not too much information about it, it seems like, you know? I want to get better, but there's not too many places (Participant_04).

Similarly, several participants - namely, those who themselves had undergone Interferon-based treatments but who continued to be living with $\mathrm{HCV}$ - expressed ongoing apprehension about accessing DAA therapies, as they anticipated that the side effects would not be tolerable. During these discussions, it became apparent that participants had not received accurate information related to DAAs, as some were unaware that many of the side effects associated with Interferon-based treatments did not apply to DAA regimens. One 41-year-old woman described her deliberation about whether or not to access treatment with DAAs, which, at the time of the interview, she was about to begin:

"I was thinking about the side effects. Yeah, what with... like, I want to know what... if I took it [DAAs], what's the side effects is, I guess. Yeah. I wouldn't know, because I don't know what kind of side effects it would affect on me, right? About taking the [DAA] pill" (Participant_03).

In some interviews, participants described a sense of mistrust and skepticism toward the interests and motivations of HCV-related public-health and pharmaceutical-research officials. By association, these participants expressed significant caution and hesitancy regarding the safety of DAA treatments. Among these participants, some expressed skepticism that they might be treated as "guinea pigs" for experimental HCV treatments, which, in some cases, contributed to hesitancy to "take up" DAAs. For instance, while being prompted about DAAs by the interviewer, one woman, who was receiving $\mathrm{HCV}$ treatment and who opted not to disclose her sociodemographic data, described: 
[DAAs] cost so much money. Now, why is it 700 dollars a pill now? This is what I was trying to find out, too: is this to cover the cost of the research before they can make the generic pills? Or, how come it costs so much money right now? [. .] Was it tested on animals? [. .] I don't want to be a guinea pig. (Participant_52).

Nonetheless, amidst descriptions of learning about DAAs, several participants expressed excitement and interest in novel HCV treatment regimens, which, as participants further described, had often been presented to them (i.e., by peers, healthcare providers, and online resources) as more tolerable and more effective medications than Interferon-based therapies. Often, participants contrasted the perceived opportunities presented by DAA treatment regimens with their previous experiences with and perceptions of Interferon-based therapies. In doing so, participants frequently characterized negative attributes of Interferon-based therapies, including their adverse side effects, prolonged treatment durations, and relative ineffectiveness when compared to DAA treatments. For instance, one 47-year-old man, who had not yet been able to access HCV treatment, described how:

I know that there was a lot of side effects to it [Interferon-based treatments]. That's what I heard about it. But the new one [DAAs] just kind of got me right off of it [referring to symptoms of low energy]. A lot of people are finding themselves getting treated of it [HCV], get cured of it, like, real quick. So yeah, the new one is way better than the old one, as far as from what I hear (Participant_07).

Concerns related to treatment side effects were further described by another participant who had not yet been able to access $\mathrm{HCV}$ treatment:

I was really scared because my friend did the [Interferon-based] treatment and he did not look the same. I thought he was going to die. [. .] That scared me, and I said I wasn't going to do it [treatment], until now I heard about the [DAA] treatments now, that they're a little bit... you don't get no side effects. So, I'm really looking forward to that, kind of thing (Participant_048; 42-year-old Two-Spirit person).

In considering participants' accounts of their histories with $\mathrm{HCV}$ and Interferon-based treatments, the data highlighted how the implementation of DAAs represents both a pivotal opportunity and a significant period of adjustment and uncertainty (e.g., related to treatment eligibility, side effects, access, and potential outcomes) for PWID living with HCV. Specifically, perceptions of DAA treatments and uptake of DAAs are deeply shaped by an array of experiential factors, including individual, interpersonal (e.g., peer influences), and community experiences with $\mathrm{HCV}$ and its treatments.

\section{Substance use and the uptake of DAA treatments: "You don't have to quit using now, but you can't miss any doses once you start treatment"}

Almost all participants described the ways in which their substance use, including alcohol, and related engagement with primary care and harm reduction services could be both a potential barrier and/or facilitator to equitable DAA treatment access. For example, in recounting their experiences across both Interferon- and DAA-based treatment eras, several participants described instances in which their substance use had been - and, in some cases, continues to be - characterized by healthcare providers as a contraindication to HCV treatment eligibility, despite this not being a policy-mandated contraindication. Indeed, the majority of participants described experiences wherein their physicians had either explicitly withheld HCV treatment, or recommended that participants stop or greatly reduce their substance use prior to accessing treatment. This denial of access to HCV treatments was described by one participant:

He [the physician] just wanted me to quit drinking [before I could start treatment], that's all. And I could see his point. Yeah, but to force me to quit drinking and then say you'll help me, that's not right. I was living in squalor. I was couch surfing and everything and I said I want to get my own place, and he wouldn't help me. [. .] Then I moved to [name of another physician], and he got me right on it [DAA treatment], and then he cured me. So, big difference of doctors, isn't it? (Participant_50; 52year-old woman, completed HCV treatment).

As illustrated above, several participants described how they responded to healthcare provider gatekeeping of DAAs by seeking out more person-centered, equityoriented, and power-balanced sources of HCV care. Participants' accounts of navigating HCV services therefore highlighted their resiliency and determination in finding service providers who did not reproduce systemic barriers to safe, nonjudgmental, and high-quality healthcare. For example, participants described how they valued healthcare providers whose approaches to $\mathrm{HCV}$ care were supportive and grounded in harm reduction, as opposed to abstinence-based approaches. One 47-year-old man, who had not yet been able to access HCV treatment, explained: 
[When I was diagnosed with $H C V$, six years ago], they [the healthcare providers] told me that it is treatable, right? But you have to be willing to stop doing this and stop doing that. I'm like, "I'm not willing to stop anything." Like, using heroin and crack and coke and all of that B.S [bullshit]. But now that I cut myself down off of everything else, and I just stick to one dope now, which is heroin, [my current physician] said, "You don't have to quit using now. You could still take your pill while you're doing whatever it is you're doing. But you can't miss any doses once you start," right? (Participant_07).

Several participants postulated that being able to have transparent and supportive discussions about their substance use facilitated open communication and the development of individualized $\mathrm{HCV}$ treatment plans. Participants further described how, in collaboration with their harm reduction-oriented healthcare providers. they had planned and implemented strategies for making $\mathrm{HCV}$ treatment more accessible and thereby more effective. These plans frequently included the integration of DAA treatments with other substance use-related services (e.g., OAT, HIV care, outreach and in-reach harm reduction services). Here, a subset of participants described how their inclination to integrate DAAs with existing services stemmed from their concerns that they might otherwise forget to take their doses (and thereby risk making the treatments ineffective); yet, the majority described how integrating services was simply a matter of convenience. One participant described how DAAs were incorporated into her daily routine of acquiring OAT (in her case, methadone) from her pharmacist:

Well, you just give it [DAAs] to them at the pharmacy then. Mine was taken every day at the pharmacy. It's what I asked of them [my physician], "When I go get my methadone, just give it to me with that." (Participant_24; 54-year-old woman, completed HCV treatment).

A subset of participants described how their treatment plans were made even more comprehensive through the involvement of multiple supports and services, including peers, partners, family, and housing and outreach workers. This support network was described as a sort of "safety net," who, if needed, could remind participants to take their DAA doses. Similarly, some participants described how logistical and organizational features of support services (e.g., extended and weekend hours of operation, the potential to carry take-home doses of DAAs from pharmacies) could serve to promote treatment accessibility and adherence. At times when they were holistically supported, participants described feeling confident and optimistic about their experiences with DAAs:

I never forget [to take my DAAs], now. [. .] I'm very vigilant now. I get up in the morning times, so I'm vigil[ant], so I know what I'm doing. [. .] And, plus, the pharmacy's aware of my situation, and knows that they have to phone me at a certain time to remind me that I have to come in. And, I'm grateful for that. Plus, I have the people at my apartment building [i.e., outreach workers] - they're aware of my situation now, too. So, they come and do an eight o'clock wake-up call with me, to remind me to take my medication. So, I've got it down (Participant_05; 53-year-old woman, undergoing HCV treatment).

Across these findings, participants described how various features of the healthcare system and providerpatient interactions could reduce barriers and thereby promote opportunities for equitable DAA access and uptake. In particular, participants described the diverging ways in which their healthcare providers had framed their substance use as either a barrier or, through harm reduction-oriented approaches, a potential avenue for engaging participants in $\mathrm{HCV}$ care, including DAA treatments.

\section{Discussion}

The introduction of universal DAA coverage in many settings, including BC, Canada, has transformed the $\mathrm{HCV}$ treatment landscape and has expanded opportunities to treat priority populations, including PWID. Yet, as these findings highlight, significant social and structural barriers to DAA treatments for PWID remain heretofore unaddressed. Drawing from participants' extensive experiences with $\mathrm{HCV}$ and related healthcare system engagement, findings from this study underscore how health and healthcare practices and policies, such as the deprioritizing of $\mathrm{HCV}$ (e.g., due to being asymptomatic, healthcare provider gatekeeping) and catalysts to care (e.g., symptom onset and burden, treatment for comorbidities), shaped experiences with and access to DAAs. More broadly, participants described how experiences with evolving $\mathrm{HCV}$ treatments (e.g. [in]eligibility, side effects, skepticism) and overarching approaches to care (e.g., abstinence-based, harm reduction-oriented, integrated) influenced motivations and opportunities related to DAA treatment access.

Findings from this study indicate that HCV-related care trajectories and clinical encounters are often fraught with uncertainty and misinformation. These findings identified how poor healthcare-provider engagement and support can lead to gaps in people's knowledge about 
$\mathrm{HCV}$, particularly with regard to potential consequences (e.g., symptoms, impacts on quality of life), as well as its treatment. Furthermore, these data underscore the extent to which stigmatizing and dehumanizing healthcare encounters, characterized by a lack empathy and respect, also prevented opportunities for PWID to acquire HCV-related information. The pronounced provider-client power imbalances as the context within which information gaps are occurring represent significant deterrents to the delivery of good care, as HCV illness- and treatment-related knowledge deficits are key barriers to DAA treatment uptake [25, 57]. To strengthen access to equitable healthcare information and treatment, it has been extensively argued that clinicians must continuously attend to power differentials and meaninfully engage clients as active participatns in care $[58,59]$. Findings from this study indicate that clinicians involved in $\mathrm{HCV}$ care must adopt equity-oriented and history-informed approaches that recognize and address the common concerns PWID may have related to $\mathrm{HCV}$ treatments (e.g., previous adverse experiences with Interferon-based therapies, concerns about DAA treatment side effects, confusion related to treatment eligibility). Unfortunately, however, previous research has indicated that specialist and primary care providers often feel they are inadequately trained to provide care that aligns with equity-oriented approaches, and are therefore insufficiently prepared to provide $\mathrm{HCV}$ and substance use-related care $[60,61]$. To comprehensively address this provider- and patient-level knowledge gap, we call for expanded advocacy and educational efforts to promote clinician capacity to provide equitable and effective care to PWID living with HCV. Indeed, these findings identify the extent to which healthcare providers need to better mitigate unequal provider-client power relations and the corresponding impacts on health and healthcare access for PWID.

Relatedly, these findings provide a critical glimpse into how structural barriers, including substance use stigma, restrict opportunities for DAA treatment uptake among PWID. For example, participants in the current study generally described how $\mathrm{HCV}$ care had tended to be deprioritized by healthcare providers on the basis of active substance use. In addition, findings from this study surfaced other clinical experiences in which guiding ethical principles of care were not followed (e.g., clinicians coldly framing HCV/HIV as a "death sentence" at the time of diagnosis). In considering these challenges, findings from this study further illustrate that the remaining barriers to HCV care identified herein (e.g., misinformation, gatekeeping) are entwined with stigmatization and mistreatment, which are well-documented determinants of HCV-related and other health and social inequities among PWID [7, 27, 30, 62-65]. These findings are consistent with previous research suggesting that PWID, including those living with $\mathrm{HCV}$, tend to be treated as passive recipients of care, not meaningfully consulted in discussions surrounding their health and wellbeing, and labelled and stigmatized within healthcare settings - and that their living circumstances (e.g., related to: substance use, income, housing) are often framed as contraindications to care, rather than carefully considered within person-centered care strategies/plans [6, 66-69]. Findings from this study therefore underscore the need for healthcare providers - particularly, those with prescriptive authorities for DAAs (e.g., physicians, nurse practitioners) - to treat PWID according to fundamental ethical principles (e.g., compassion, dignity, respect for persons) underpinning clinician codes of ethics for socially just clinical practice (e.g., [70, 71]). Further, these findings highlight the importance of facilitating access to $\mathrm{HCV}$ care while taking seriously the need for larger scale system-level and structural changes and "upstream" policy responses (e.g., safe housing for everyone).

Acknowledging the colonial context in $\mathrm{BC}$, the perspectives of Indigenous Peoples in this study sample, and the harmful clinical encounters described herein, findings from this study also align with a growing body of Canadian and international empirical evidence highlighting how $\mathrm{HCV}$-affected Indigenous Peoples are distinctly and inequitably mistreated within healthcare settings [26, 72-74]. For Indigenous Peoples, including those who use substances and who face substance use stigma, historical and ongoing contexts of systemic racism and colonialism are known to create barriers to safe, effective, and timely healthcare [58, 75]. To mitigate ongoing health inequities, including those stemming from structural barriers to clinical care, $\mathrm{HCV}$ treatment providers must take meaningful action to create and maintain relationships that are safe and trauma- and history-informed, and that promote equitable access to care, information, and treatment for Indigenous and other PWID living with HCV. Here, there is a critical need for culturally safe approaches that foreground social justice goals in HCV care provision and that include clinician "critical self-refection of biases, acknowledgement of power imbalances, and conviction to uphold Indigenous [and non-Indigenous] patient selfdetermination at every step of the HCV cascade of care" (26p60), along with structural interventions to redress inequities related to $\mathrm{HCV}$ treatment, care and outcomes.

To further optimize DAA treatment experiences among PWID, these findings also indicate the need for system-level changes, including the provision of lowbarrier, integrated, and peer-led services. For example, participants emphasized how their relationships with harm reduction-oriented healthcare providers facilitated opportunities to develop comprehensive $\mathrm{HCV}$ treatment 
plans, which included linking DAAs with existing services that many PWID already access - the feasibility and effectiveness of which has documented elsewhere, such as in the contexts of HIV care $[76,77]$ and OAT provision [18, 78-82]. In addition, participants described how efforts from community members and housingsupport workers to facilitate and uphold DAA treatments plans (e.g., through "check-ins" and reminders to take medications) further contributed to the consistent uptake of DAA treatments. The importance of peer and social supports was further echoed in participants' descriptions of community members as trusted sources of knowledge who essentially vouched for DAAs, such as by alleviating potential concerns (e.g., related to side effects and eligibility) and by substantiating the safety and effectiveness of novel treatments. These findings align with recent research underscoring the influence of peers (i.e., other PWID with lived experience of $\mathrm{HCV}$ ) on health seeking behaviours and the spread of health information, particularly in regard to DAA treatments [20,83-85]. To further promote linkages to $\mathrm{HCV}$ care and the equitable scale-up of DAAs among PWID, additional public health efforts to implement and optimize peer-driven and network-based interventions are warranted.

This study has several strengths and limitations. The large and diverse sample of PWID who have lived experience with HCV yielded highly-contextualized descriptions of $\mathrm{HCV}$ care across both Interferon- and DAA-based treatment eras. Nevertheless, we acknowledge that the perspectives of other stakeholders in $\mathrm{HCV}$ care (e.g., peers, family members, clinicians, policymakers) were beyond the scope of this research. In addition, limitations in the study design and the specificity of the research questions hindered our ability to meaningfully investigate how perceptions and experiences with DAAs vary across and within subpopulations of PWID (e.g., across axes of ethnocultural identity, socio-economic status, sexuality, gender identity, and HIV serostatus; across participants' "types" and contexts of substance use); we were therefore unable to delineate significant differences across these population subgroups. Further research is needed to explicate ways in which access to DAA treatment is embedded within intersecting socio-structural contexts, and how these contexts may differentially impact PWID based on various aspects of social location. Similarly, although participants often contrasted their experiences with DAAs to their past experiences during the Interferon-based $\mathrm{HCV}$ treatment era, we had not explicitly sought to investigate changes in these experiences over time. Historical and/ or longitudinal analyses of evolving HCV care landscapes could offer additional insights into the ways in which policy and programmatic transformations directly influence the health experiences and outcomes of PWID with lived experience of $\mathrm{HCV}$.

\section{Conclusions}

The introduction of novel DAA treatments and the subsequent removal of regulatory barriers to access these medications in many settings, including BC, Canada, has renewed optimism for expanding HCV treatment efforts. To further promote the equitable scale-up of DAAs among PWID, comprehensive approaches that account for the socio-structural and historical factors that have influenced HCV-related health and healthcare access for this population are needed. Findings from this study underscore several healthcare and service delivery transformations that are required to meaningfully facilitate PWID's access to DAA treatments, including the scaleup of integrated services and peer- and communitybased interventions and supports, alongside the championing of equity-oriented clinician approaches to care that are attentive to power differentials and the social contexts of people's lives, culturally safe and nonstigmatizing, and grounded in harm reduction.

\section{Abbreviations \\ BC: British Columbia; DAA: Direct-acting antiviral; HCV: Hepatitis C virus; HIV: Human immunodeficiency virus; PWID: People who inject drugs; OAT: Opioid agonist therapy}

\section{Acknowledgements}

We are thankful to the people who shared their time and stories for this research. We are also thankful to Nahal Torabi for completing much of the initial coding of the data.

\section{Authors' contributions}

TG led the analysis of data and conceptualized, wrote, and revised the manuscript. RK conceptualized the study, obtained study funding, contributed to data collection and analysis, and provided mentorship in writing this manuscript. $\mathrm{HB}$ and AJB contributed to data analysis and provided mentorship in conceptualizing, writing, and revising the manuscript. PH led data collection and contributed to data analysis and manuscript revision. LT contributed to data analysis and offered critical revisions to the manuscript. All authors read and approved the final manuscript.

\section{Funding}

This study was funded by the Canadian Institutes of Health Research (Grant PJT-148922). TG receives trainee support through the Canadian Nurses Foundation, the US National Institute of Drug Abuse (Grant R25-DA033756), and the University of British Columbia. RK and LT are supported by Scholar Awards from the Michael Smith Foundation for Health Research.

\section{Availability of data and materials}

The data analyzed during the current study are not publicly available because they contain information that could compromise research participant privacy and consent, but are available from the corresponding author on reasonable request.

\section{Declarations}

Ethics approval and consent to participate

Ethics approval for this study was obtained from the University of British Columbia Behavioural Research Ethics Board (\#H16-02943). Participants provided written informed consent. 


\section{Consent for publication}

Not applicable.

\section{Competing interests}

The authors declare that they have no competing interests.

\section{Author details}

${ }^{1}$ School of Nursing, University of British Columbia, Vancouver, Canada. ${ }^{2}$ British Columbia Centre on Substance Use, 400-1045 Howe St, V6Z 2 A9 Vancouver, BC, Canada. ${ }^{3}$ Department of Medicine, University of British Columbia, Vancouver, Canada.

\section{Received: 16 October 2020 Accepted: 4 March 2021}

Published online: 19 March 2021

\section{References}

1. World Health Organization. Guidelines for the care and treatment of persons diagnosed with chronic hepatitis C virus infection. Geneva: World Health Organization; 2018.

2. Chou R, Hartung D, Rahman B, Wasson N, Cottrell EB, Fu R. Comparative effectiveness of antiviral treatment for hepatitis $C$ virus infection in adults: $A$ systematic review. Ann Intern Med. 2013;158(2):114

3. Janjua NZ, Islam N, Wong J, Yoshida EM, Ramji A, Samji H, et al. Shift in disparities in hepatitis $C$ treatment from interferon to DAA era: $A$ population-based cohort study. J Viral Hepatitis. 2017;24(8):624-30.

4. Aspinall EJ, Corson S, Doyle JS, Grebely J, Hutchinson SJ, Dore GJ, et al. Treatment of hepatitis $C$ virus infection among people who are actively injecting drugs: A systematic review and meta-analysis. Clin Infect Dis. 2013; 57(suppl_2):80-S9.

5. Janjua NZ, Kuo M, Yu A, Alvarez M, Wong S, Cook D, et al. The population level cascade of care for hepatitis $C$ in British Columbia, Canada: The BC Hepatitis Testers Cohort (BC-HTC). EBioMedicine. 2016;12:189-95.

6. Heffernan A, Cooke GS, Nayagam S, Thursz M, Hallett TB. Scaling up prevention and treatment towards the elimination of hepatitis $C$ : a global mathematical model. The Lancet. 2019:393(10178):1319-29.

7. Ford N, Wiktor S, Kaplan K, Andrieux-Meyer I, Hill A, Radhakrishnan P, et al. Ten priorities for expanding access to HCV treatment for people who inject drugs in low- and middle-income countries. Int J Drug Policy. 2015;26(11): 1088-93.

8. World Health Organization. Global health sector strategy on viral hepatitis 2016-2021: Towards ending viral hepatitis. Geneva: World Health Organization; 2016

9. Høj SB, Jacka B, Minoyan N, Artenie AA, Bruneau J. Conceptualising access in the direct-acting antiviral era: An integrated framework to inform research and practice in HCV care for people who inject drugs. The International journal of drug policy. 2019;72:11-23.

10. Knight $R$, Ti L. The successful scale-up of direct-acting antiviral hepatitis C treatments will benefit from concerted investments in implementation science. Can J Public Health. 2019;110(3):376-9.

11. Grebely J, Larney S, Peacock A, Colledge S, Leung J, Hickman M, et al. Global, regional, and country-level estimates of hepatitis $C$ infection among people who have recently injected drugs. Addiction. 2019;114(1):150-66

12. Trickey A, Fraser H, Lim AG, Peacock A, Colledge S, Walker JG, et al. The contribution of injection drug use to hepatitis $C$ virus transmission globally, regionally, and at country level: A modelling study. The Lancet Gastroenterology Hepatology. 2019;4(6):435-44.

13. Bird K, Socías ME, Ti L. Integrating hepatitis $C$ and addiction care for people who inject drugs in the era of direct-acting antiviral therapy. Int J Drug Policy. 2018:59:1-2.

14. Degenhardt L, Peacock A, Colledge S, Leung J, Grebely J, Vickerman P, et al. Global prevalence of injecting drug use and sociodemographic characteristics and prevalence of HIV, HBV, and HCV in people who inject drugs: A multistage systematic review. The Lancet Global Health. 2017;5(12): e1192-e207.

15. Socías ME, Ti L, Dong H, Shoveller J, Kerr T, Montaner J, et al. High prevalence of willingness to use direct-acting antiviral-based regimens for hepatitis C virus (HCV) infection among HIV/HCV coinfected people who use drugs. HIV Med. 2017;18(9):647-54.

16. Blach S, Zeuzem S, Manns M, Altraif I, Duberg A-S, Muljono DH, et al. Global prevalence and genotype distribution of hepatitis $C$ virus infection in 2015: a modelling study. 2017.
17. Ha S, Totten S, Pogany L, Wu J, Gale-Rowe M. Hepatitis C in Canada and the importance of risk-based screening. Can Comm Dis Rep. 2016;42(11):57-62.

18. Litwin AH, Drolet M, Nwankwo C, Torrens M, Kastelic A, Walcher S, et al. Perceived barriers related to testing, management and treatment of HCV infection among physicians prescribing opioid agonist therapy: The CSCOPE Study. J Viral Hepatitis. 2019;26(9):1094-104.

19. Marshall AD, Grebely J, Dore GJ, Treloar C. Barriers and facilitators to engaging in hepatitis $C$ management and DAA therapy among general practitioners and drug and alcohol specialists-The practitioner experience. Drug Alcohol Depend. 2020;206:107705.

20. Goodyear T, Ti L, Carrieri P, Small W, Knight R. "Everybody living with a chronic disease is entitled to be cured": Challenges and opportunities in scaling up access to direct-acting antiviral hepatitis $C$ virus treatment among people who inject drugs. Int J Drug Policy. 2020;81:102766.

21. Skeer MR, Ladin K, Wilkins LE, Landy DM, Stopka TJ. 'Hep C's like the common cold': Understanding barriers along the HCV care continuum among young people who inject drugs. Drug Alcohol Depend. 2018;190: 246-54.

22. Clark JA, Gifford AL. Resolute efforts to cure hepatitis C: Understanding patients' reasons for completing antiviral treatment. Health. 2015;19(5):47389.

23. Rhodes T, Harris M, Martin A. Negotiating access to medical treatment and the making of patient citizenship: the case of hepatitis $C$ treatment. Sociol Health IIIn. 2013;35(7):1023-44.

24. Jordan AE, Masson CL, Mateu-Gelabert P, McKnight C, Pepper N, Bouche K, et al. Perceptions of drug users regarding hepatitis $C$ screening and care: $A$ qualitative study. Harm reduction journal. 2013;10(1):10-.

25. Madden A, Hopwood M, Neale J, Treloar C. Beyond interferon side effects: What residual barriers exist to DAA hepatitis $C$ treatment for people who inject drugs? PloS one. 2018;13(11):e0207226.

26. Pearce ME, Jongbloed $K$, Demerais L, MacDonald H, Christian WM, Sharma $\mathrm{R}$, et al. "Another thing to live for": Supporting HCV treatment and cure among Indigenous people impacted by substance use in Canadian cities. Int J Drug Policy. 2019;74:52-61.

27. Grebely J, Bruneau J, Bruggmann P, Harris M, Hickman M, Rhodes T, et al. Elimination of hepatitis $C$ virus infection among PWID: The beginning of a new era of interferon-free DAA therapy. Int J Drug Policy. 2017;47:26-33.

28. Sims OT, Guo Y, Shoreibah MG, Venkata K, Fitzmorris P, Kommineni V, et al. Short article: Alcohol and substance use, race, and insurance status predict nontreatment for hepatitis $C$ virus in the era of direct acting antivirals: $A$ retrospective study in a large urban tertiary center. Eur J Gastroenterol Hepatol. 2017;29(11):1219-22.

29. Asher AK, Portillo CJ, Cooper BA, Dawson-Rose C, Vlahov D, Page KA. Clinicians' views of hepatitis C virus treatment candidacy with direct-acting antiviral regimens for people who inect drugs. Subst Use Misuse. 2016;51(9): 1218-23.

30. Mah A, Hull MW, DeBeck K, Milloy MJ, Dobrer S, Nosova E, et al. Knowledge of hepatitis $C$ and treatment willingness amongst people who inject drugs in an era of direct acting antivirals. Int J Drug Policy. 2017:47:137-43.

31. Browne AJ, Reimer-Kirkham S. Problematizing social justice discourses in nursing. In: Varcoe C, Browne AJ, Cender LM, editors. Philosophies and practices of emancipatory nursing: Social justice as praxis 1ed. New York: Routledge; 2014. pp. 21-38.

32. Varcoe C, Browne AJ, Cender L. Promoting social justice and equity by practicing nursing to address structural inequities and structural violence. In: Kagan P, Smith M, Chinn P, editors. Philosophies and practices of emancipatory nursing: Social justice as praxis. New York: Routledge; 2014. pp. 266-84.

33. Browne AJ, Varcoe C, Ford-Gilboe M, Nadine Wathen C, Smye V, Jackson $\mathrm{BE}$, et al. Disruption as opportunity: Impacts of an organizational health equity intervention in primary care clinics. Int J Equity Health. 2018;17(1): 154-16.

34. Charmaz K. Constructing grounded theory. 2 ed. Thousand Oaks: Sage; 2014

35. Creswell JW, Poth CN. Data analysis and representation. Qualitative inquiry and research design: Choosing among five approaches. 4 ed. Thousand Oaks: SAGE Publicatoins, Inc.; 2018. pp. 181-224.

36. Statistics Canada. Population and dwelling count highlight tables: 2016 Census: Statistics Canada; 2016 [updated 2019-02-20. Available from: $\mathrm{cfm}$ ?Lang $=$ Eng $\& T=701 \& S R=1 \& S=3 \& \mathrm{O}=\mathrm{D} \& \mathrm{RPP}=9999 \& \mathrm{PR}=59$. 
37. Lazatin LS. B.C. expands drug coverage to anyone suffering from chronic hepatitis C. 2018 March 13.

38. Bartlett SR, Yu A, Chapinal N, Rossi C, Butt Z, Wong S, et al. The population level care cascade for hepatitis C in British Columbia, Canada as of 2018: Impact of direct acting antivirals. Liver International. 2019;39(12):2261-72.

39. Truth and Reconciliation Commission of Canada. Honouring the truth, reconciling for the future: Summary of the final report of the Truth and Reconciliation Commission of Canada. Winnipeg: Book, Whole; 2014. Report No : 145941067X;1459410688;9781459410688\$49781459410671; Contract No.

40. National Inquiry into Missing and Murdered Indigenous Women and Girls. Reclaiming power and place: Final report of the National Inquiry into Missing and Murdered Indigenous Women and Girls: Privy Council Office U6; 2019.

41. Browne AJ. Moving beyond description: Closing the health equity gap by redressing racism impacting Indigenous populations. Soc Sci Med. 2017;184: 23-6.

42. Greenwood M, De Leeuw S, Lindsay NM. Determinants of Indigenous peoples' health: Beyond the social. Second ed. Toronto: Canadian Scholars; 2018.

43. Marshall SG. Canadian drug policy and the reproduction of Indigenous inequities. International Indigenous Policy Journal. 2015;6(1).

44. de Leeuw S, Greenwood M, Cameron E. Deviant constructions: How governments preserve colonial narratives of addictions and poor mental health to intervene into the lives of Indigenous children and families in Canada. International Journal of Mental Health Addiction. 2010;8(2):282-95.

45. Boucher R, King A, Lavand D, Nicholson V, Ryan C, Denys RS, et al. Policy brief: Indigenous harm reduction = reducing harms of colonialism. 2019 .

46. McKenzie HA, Dell CA, Fornssler B. Understanding addictions among Indigenous people through social determinants of health frameworks and strength-based approaches: A review of the research Iterature from 2013 to 2016. Current Addiction Reports. 2016;3(4):378-86.

47. Skinner S, Cote G, Khan I. Hepatitis C virus infection in Saskatchewan First Nations communities: Challenges and innovations. Canada communicable disease report $=$ Releve des maladies transmissibles au Canada. 2018;44(78):173-8.

48. Gordon J, Bocking N, Pouteau K, Farrell T, Ryan G, Kelly L. First Nations hepatitis $C$ virus infections: Six-year retrospective study of on-reserve rates of newly reported infections in northwestern Ontario. Canadian family physician Medecin de famille canadien. 2017;63(11):e488-e94.

49. Nitulescu R, Young J, Saeed S, Cooper C, Cox J, Martel-Laferriere V, et al. Variation in hepatitis $C$ virus treatment uptake between Canadian centres in the era of direct-acting antivirals. Int J Drug Policy. 2019;65:41-9.

50. Saeed S, Strumpf EC, Moodie EEM, Young J, Nitulescu R, Cox J, et al. Disparities in direct acting antivirals uptake in HIV-hepatitis C co-infected populations in Canada. J Int AIDS Soc. 2017;20(3):e25013.

51. Rempel JD, Uhanova J. Hepatitis $C$ virus in American Indian/Alaskan Native and Aboriginal peoples of North America. Viruses. 2012;4(12):3912-31.

52. Jongbloed K, Pearce ME, Pooyak S, Zamar D, Thomas V, Demerais L, et al. The Cedar Project: Mortality among young Indigenous people who use drugs in British Columbia. CMAJ: Canadian Medical Association journal = journal de I'Association medicale canadienne. 2017;189(44): E1352-E9.

53. Palinkas LA, Horwitz SM, Green CA, Wisdom JP, Duan N, Hoagwood K. Purposeful sampling for qualitative data collection and analysis in mixed method implementation research. Adm Policy Ment Health. 2015; 42(5):533-44.

54. Kennedy MC, Hayashi K, Milloy MJ, Boyd J, Wood E, Kerr T. Supervised injection facility use and exposure to violence among a cohort of people who inject drugs: A gender-based analysis. Int J Drug Policy. 2020;78: 102692.

55. British Columbia Centre for Excellence in HIV/AIDS. Per-SVR 2020 [Available from:

56. Carrier L, Dame J, Lane J. Two-Spirit identity and Indigenous conceptualization of gender and sexuality: Implications for nursing practice. Creative Nursing. 2020;26(2):96-100.

57. Marshall AD, Micallef M, Erratt A, Telenta J, Treloar C, Everingham $H$, et al. Liver disease knowledge and acceptability of non-invasive liver fibrosis assessment among people who inject drugs in the drug and alcohol setting: The LiveRLife Study. Int I Drug Policy. 2015;26(10):984-91.
58. Browne AJ, Varcoe C, Lavoie J, Smye V, Wong ST, Krause M, et al. Enhancing health care equity with Indigenous populations: evidence-based strategies from an ethnographic study. BMC Health Serv Res. 2016;16(1):544.

59. Pauly B. Shifting moral values to enhance access to health care: Harm reduction as a context for ethical nursing practice. Int J Drug Policy. 2008; 19(3):195-204

60. Chan J, Young J, Cox J, Nitulescu R, Klein MB. Patterns of practice and barriers to care for hepatitis $C$ in the direct-acting antiviral (DAA) era: A national survey of Canadian infectious diseases physicians. Canadian Liver Journal. 2018;1 (4):231-9.

61. Myers RP, Shah H, Burak KW, Cooper C, Feld JJ. An update on the management of chronic hepatitis C: 2015 Consensus guidelines from the Canadian Association for the Study of the Liver. Canadian Journal of Gastroenterology Hepatology. 2015;29(1):19-34.

62. Crowley D, Van Hout MC, Lambert JS, Kelly E, Murphy C, Cullen W. Barriers and facilitators to hepatitis $\mathrm{C}(\mathrm{HCV})$ screening and treatment-a description of prisoners' perspective. Harm Reduct J. 2018;15(1):62.

63. Harris M, Rhodes T, Martin A. Taming systems to create enabling environments for $\mathrm{HCV}$ treatment: Negotiating trust in the drug and alcohol setting. Soc Sci Med. 2013;83:19-26.

64. Neale J. Homelessness, drug use and hepatitis C: A complex problem explored within the context of social exclusion. Int J Drug Policy. 2008;19(6): 429-35.

65. Stone J, Martin NK, Hickman M, Hutchinson SJ, Aspinall E, Taylor A, et al. Modelling the impact of incarceration and prison-based hepatitis $C$ virus ( $\mathrm{HCV}$ treatment on $\mathrm{HCV}$ transmission among people who inject drugs in Scotland. Addiction. 2017;112(7):1302-14.

66. Simha A, Maria Webb C, Prasad R, Kolb NR, Veldkamp PJ. Moral distress with obstacles to hepatitis C treatment: A Council of Academic Family Medicine Educational Research Alliance (CERA) study of family medicine program directors. J Am Board Fam Med. 2018;31(2):286-91.

67. Rossi C, Butt ZA, Wong S, Buxton JA, Islam N, Yu A, et al. Hepatitis C virus reinfection after successful treatment with direct-acting antiviral therapy in a large population-based cohort. J Hepatol. 2018;69(5):1007-14.

68. Brener L, Resnick I, Ellard J, Treloar C, Bryant J. Exploring the role of consumer participation in drug treatment. Drug Alcohol Depend. 2009; 105(1):172-5.

69. Harris M, Rhodes T. Hepatitis C treatment access and uptake for people who inject drugs: A review mapping the role of social factors. Harm Reduction Journal. 2013;10(1):1-11.

70. Canadian Nurses Association. Code of ethics for registered nurses. Ottawa, ON; 2017. Report No.: $9781551194417 \$ 4$.

71. Canadian Medical Association. CMA code of ethics and professionalism. 2018.

72. Treloar C, Jackson LC, Gray R, Newland J, Wilson H, Saunders V, et al. Multiple stigmas, shame and historical trauma compound the experience of Aboriginal Australians living with hepatitis C. Health Sociology Review. 2016; 25(1):18-32.

73. Brener L, Wilson H, Jackson LC, Johnson P, Saunders V, Treloar C. The role of Aboriginal community attachment in promoting lifestyle changes after hepatitis C diagnosis. Health psychology open. 2015;2(2):2055102915601581.

74. Brener L, Wilson H, Jackson LC, Johnson P, Saunders V, Treloar C. Experiences of diagnosis, care and treatment among Aboriginal people living with hepatitis C. Aust N Z J Public Health. 2016;40(S1):59-64.

75. Public Health Agency of Canada. Addressing stigma: Towards a more inclusive health system. The Chief Public Health Officer's report on the state of public health in Canada 2019. Ottawa: Public Health Agency of Canada; 2019.

76. Chuah FLH, Haldane VE, Cervero-Liceras F, Ong SE, Sigfrid LA, Murphy G, et al. Interventions and approaches to integrating HIV and mental health services: a systematic review. Health Policy Plan. 2017;32(suppl_4):iv27-47.

77. Falade-Nwulia O, Sutcliffe C, Moon J, Chander G, Wansom T, Keruly J, et al. High hepatitis $C$ cure rates among black and nonblack human immunodeficiency virus-infected adults in an urban center. Hepatology. 2017;66(5):1402-12.

78. Butner JL, Gupta N, Fabian C, Henry S, Shi JM, Tetrault JM. Onsite treatment of HCV infection with direct acting antivirals within an opioid treatment program. J Subst Abuse Treat. 2017;75:49-53.

79. Christensen S, Buggisch P, Mauss S, Boker KHW, Schott E, Klinker H, et al, Direct-acting antiviral treatment of chronic HCV-infected patients on opioid 
substitution therapy: Still a concern in clinical practice? Addiction. 2018; 113(5):868-82.

80. Panagiotoglou D, Krebs E, Min JE, Olding M, Ahamad K, Ti L, et al. Initiating HCV treatment with direct acting agents in opioid agonist treatment: When to start for people co-infected with HIV? Int J Drug Policy. 2017;47:169-76.

81. Cousien A, Leclerc P, Morissette C, Bruneau J, Roy E, Tran VC, et al. The need for treatment scale-up to impact HCV transmission in people who inject drugs in Montreal, Canada: a modelling study. BMC Infect Dis. 2017;17(1): 162.

82. Talal AH, Thomas DL, Reynolds JL, Khalsa JH. Toward optimal control of hepatitis $C$ virus infection in persons with substance use disorders. Ann Intern Med. 2017;166(12):897-8.

83. Falade-Nwulia O, Sacamano P, McCormick SD, Yang C, Kirk G, Thomas D, et al. Individual and network factors associated with HCV treatment uptake among people who inject drugs. Int J Drug Policy. 2020;78:102714.

84. Falade-Nwulia O, Ward KM, McCormick S, Mehta SH, Pitts SR, Katz S, et al. Network-based recruitment of people who inject drugs for hepatitis $C$ testing and linkage to care. Journal of viral hepatitis. 2020.

85. Jacob J, Ti L, Knight R. Will peer-based interventions improve hepatitis $C$ virus treatment uptake among young people who inject drugs? Canadian Journal of Public Health. 2020.

\section{Publisher's Note}

Springer Nature remains neutral with regard to jurisdictional claims in published maps and institutional affiliations.

Ready to submit your research? Choose BMC and benefit from:

- fast, convenient online submission

- thorough peer review by experienced researchers in your field

- rapid publication on acceptance

- support for research data, including large and complex data types

- gold Open Access which fosters wider collaboration and increased citations

- maximum visibility for your research: over $100 \mathrm{M}$ website views per year

At BMC, research is always in progress.

Learn more biomedcentral.com/submissions 